Instrumental Achievements

\title{
Rapid Analysis of Light Hydrocarbons and Carbon Dioxide in Air with Micro Thermal Conductivity Detector
}

\author{
Akira Machino, Hideo Sugimoto and Daijiro Terasaki \\ Fundamental Technology Research Laboratory, Tokyo Gas Co., Ltd., \\ Shibaura, Minato, Tokyo 105, Japan
}

Light hydrocarbons, such as methane, ethane, propane and butane, are sometimes detected in air at concentrations of several ppm. Such amounts are thought to originate from fermentation gas, petroleum gas, or city gas. It is very important for identifying gas origin to be able to analyze minor components such as light hydrocarbons and carbon dioxide. In our previous study $^{1}$, a fully automated gas chromatograph system was developed to measure these compounds rapidly. This system was composed of packed columns and 7 detectors (TCD 4, FID 2, PID 1); it took $25-40 \mathrm{~min}$ to analyze one sample.

The last few years have seen dramatic developments in the application of capillary columns. Now the rapid analysis of light hydrocarbons can be accomplished using a capillary column with an FID. A TCD is generally used for the simultaneous analysis of light hydrocarbons and inorganic components such as carbon dioxide. However, it is seldom combined with capillary columns owing to the detector cell volume and sensitivity. A few years ago, Saadat and Terry ${ }^{2}$ reported the development of a microchip TCD-GC, also known as the "GC on a chip". This micro-TCD was made by an etching technique called silicone micromachining and had a high sensitivity. A gas chromatograph such as a micro-TCD has recently been commercialized. ${ }^{3-5}$ Columns packed with alumina, molecular sieves, or porous polymers have been generally used for the analysis of inorganic gases and light hydrocarbons. In recent years, porous layer open tubular (PLOT) capillary columns coated with these materials have also become commercially available by new coating techniques. ${ }^{6,7}$ In this study, we combined the micro-TCD with PLOT-type capillary columns to accomplish the rapid analysis of light hydrocarbons and carbon dioxide in air. We also investigated the optimum analytical conditions and developed the portable gas analyzer on the basis of these results.

\section{Experimental}

The characteristic features of the columns used in this study are listed in Table 1. The lengths of these columns ranged from $0.5-10 \mathrm{~m}$. The capillary column was mounted in the splitless mode on an M-200 gas chromatograph (Nippon Tylan Co., Ltd.) equipped with a TCD. Helium was used as the carrier gas. Carbon dioxide and methane-butane gases were obtained from Takachiho Chemical Co., Ltd. These gases were arbitrarily mixed with air and used as the specimen gases.

\section{Results and Discussion}

Table 2 shows the results of the experiments on several capillary columns. Separation of inorganic gases and light hydrocarbons was unsatisfactory on a short capillary column coated with a liquid stationary phase like methylsilicone, even at lower column temperatures such as $303 \mathrm{~K}$. With $\mathrm{Al}_{2} \mathrm{O}_{3} / \mathrm{KCl}$ PLOT and Molsieve 5A PLOT, the retention time of light hydrocarbons decreased after the analysis of air was repeated many times. This phenomenon must be caused by adsorption of water and carbon dioxide in air into the stationary particles, resulting in a change of adsorption characteristics. To reduce times for component analyses, either programmed temperature gas chromatography on sole column or isothermal gas

Table 1 Characteristic features of various columns

\begin{tabular}{lcccl}
\hline Stationary phase & Length $/ \mathrm{m}$ & Inner diameter $/ \mathrm{mm}$ & Film thickness $/ \mu \mathrm{m}$ & Remarks \\
\hline Porous polymer & $0.5-10$ & 0.32 & 10 & PoraPLOT Q \\
Alumina & 4 & 0.32 & 5 & $\mathrm{Al}_{2} \mathrm{O}_{3} /$ KCl PLOT \\
Molecular sieve & 4 & 0.32 & 30 & Molsieve 5A PLOT $^{\text {PA }}$ \\
Methylsilicone & 4 & 0.10 & 10 & DB-1 \\
\hline
\end{tabular}


Table 2 Retention time of various components

\begin{tabular}{|c|c|c|c|c|c|c|c|c|c|c|c|}
\hline \multirow{3}{*}{ Column } & \multicolumn{2}{|c|}{ Analytical condition } & \multirow{2}{*}{\multicolumn{9}{|c|}{ Retention time/s }} \\
\hline & \multirow{2}{*}{$\begin{array}{c}\text { Column } \\
\text { temperature } / \\
\mathbf{K}\end{array}$} & \multirow{2}{*}{$\begin{array}{c}\text { Carrier gas } \\
\text { velocity/ } \\
\mathrm{cm} \mathrm{s}^{-1}\end{array}$} & & & & & & & & & \\
\hline & & & $\mathrm{O}_{2}$ & $\mathrm{~N}_{2}$ & $\mathrm{CH}_{4}$ & $\mathrm{C}_{2} \mathrm{H}_{6}$ & $\mathrm{C}_{3} \mathrm{H}_{8}$ & $i-\mathrm{C}_{4} \mathrm{H}_{10}$ & $n-\mathrm{C}_{4} \mathrm{H}_{10}$ & $\mathrm{CO}_{2}$ & $\mathrm{H}_{2} \mathrm{O}$ \\
\hline DB-1 (4 m) & 303 & 20 & 21 & 21 & 21 & 21 & 21.5 & 22 & 24 & 21 & 22 \\
\hline $\mathrm{Al}_{2} \mathrm{O}_{3} / \mathrm{KCl}$ PLOT (4 m) & 303 & 20 & 42 & 42 & 42 & 42 & 58 & 101 & 112 & - & - \\
\hline Molsieve 5A PLOT (4 m) & 323 & 20 & 35 & 54 & 104 & - & - & - & - & - & - \\
\hline \multirow{2}{*}{ PoraPLOT Q (4 m) } & 303 & 20 & 41 & 41 & 43 & 92 & - & - & - & 54 & 157 \\
\hline & 353 & 20 & 20 & 20 & 20 & 22 & 62 & 135 & 171 & 20 & 36 \\
\hline
\end{tabular}

-: not eluted within $255 \mathrm{~s}$.

chromatography on coupled columns for low and high boiling point gas fractions can be applied. But the former method takes a lot of time to adjust column overtemperature to an initial state at every zero hour of GC run. Therefore, the latter two column methods were examined. As shown in Table 2, methane, ethane and carbon dioxide could be separated on a PoraPLOT $Q$ at $303 \mathrm{~K}$ within $100 \mathrm{~s}$, and propane, isobutane, and butane could be separated at $353 \mathrm{~K}$ within $180 \mathrm{~s}$. We decided to employ an analytical system in which one PoraPLOT Q column was used for analyzing methane, ethane and carbon dioxide at a low column temperature, while the analysis of propane, isobutane and butane was performed with another PoraPLOT Q column at a high column temperature.

In order to determine optimum flow rate for analyzing mixtures of light hydrocarbons and inorganic gases, we investigated the Van Deemter curves for methane, ethane and carbon dioxide. HETP becomes a minimum at 15 to $25 \mathrm{~cm} / \mathrm{s}$. The minimum values of HETP are about $1.2 \mathrm{~mm}$.

Table 3 shows the relationship between column length and the resolution value, which was estimated by air $\left(\mathrm{N}_{2}+\mathrm{O}_{2}\right)$ and methane. As shown in Table 3, a column length needs more than $8 \mathrm{~m}$ to separate air and methane completely. Figure 1 shows a typical chromatogram of air, methane, ethane and carbon dioxide. These components could be analyzed within $180 \mathrm{~s}$ and the minimum limit of detection of ethane $(S / N=3)$ was $3 \mathrm{ppm}$ under these conditions.

Detailed studies of the characteristics of the PoraPLOT Q column for hydrocarbons have already been reported by Zeeuw et al. ${ }^{8,9}$ However, data are not available on the separation of hydrocarbons and water. The effect of column temperature on the separation of propane and water was investigated in the range of 313 $353 \mathrm{~K}$. It was found that it was difficult to detect the trace hydrocarbons at lower temperatures because the tailing of the water peak became larger at such temperatures. However, the tailing was extremely small at $353 \mathrm{~K}$. This phenomenon might have been due to the decrease in intermolecular forces between water and the surfaces of porous polymers. Table 4 shows the effect of column length on the resolution of water and
Table 3 Dependence of peak resolution of air and methane on column length

\begin{tabular}{cc}
\hline Column length $/ \mathrm{m}$ & Resolution value \\
\hline 4 & 0.64 \\
6 & 1.14 \\
8 & 1.87 \\
10 & 2.11 \\
\hline
\end{tabular}

Column, PoraPLOT Q; temperature, $313 \mathrm{~K}$; carrier gas velocity, $25 \mathrm{~cm} / \mathrm{s}$.

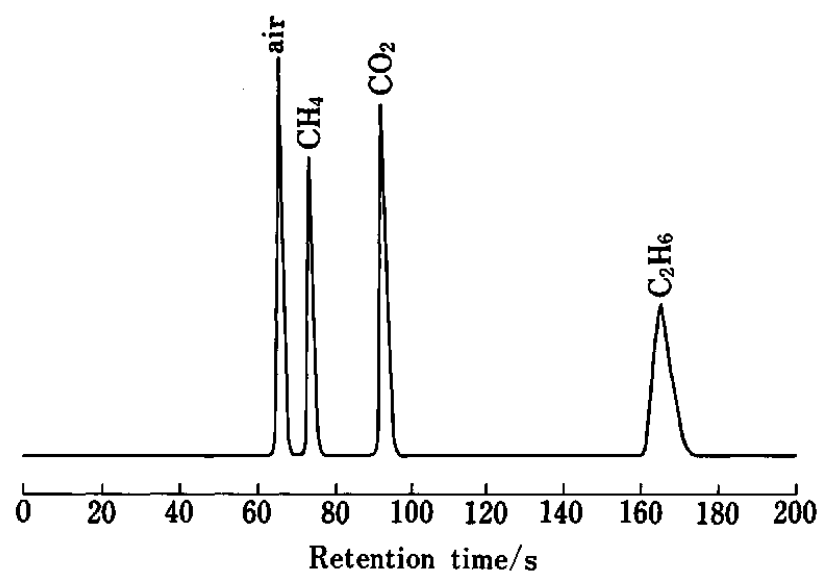

Fig. 1 Chromatogram of methane, carbon dioxide and ethane obtained with PoraPLOT Q column: column length, $8 \mathrm{~m}$; temperature, $313 \mathrm{~K}$; linear velocity, $25 \mathrm{~cm} / \mathrm{s}$.

propane. Propane was separated from water by a $2 \mathrm{~m}$ long column. Figure 2 shows a typical chromatogram of air, water, propane, isobutane and butane. These components could be analyzed within $100 \mathrm{~s}$ and the minimum limit of detection of propane $(S / N=3)$ was 3 ppm under these conditions.

A portable gas analyzer was developed based on the above experimental results. It is small and compact (width: $430 \mathrm{~mm}$, depth: $390 \mathrm{~mm}$, and height: $120 \mathrm{~mm}$ ); its weight is $9 \mathrm{~kg}$. It has 2 independent analyzing 
Table 4 Dependence of peak resolution of water and propane on column length

\begin{tabular}{cc}
\hline Column length $/ \mathrm{m}$ & Resolution value \\
\hline 0.25 & 0 \\
0.5 & 0.5 \\
1 & 1.3 \\
2 & 3.2 \\
4 & 7.9 \\
\hline
\end{tabular}

Column, PoraPLOT Q; temperature, $353 \mathrm{~K}$; carrier gas velocity, $20 \mathrm{~cm} / \mathrm{s}$.



Fig. 2 Chromatogram of propane, isobutane and butane obtained with PoraPLOT Q column: column length, $2 \mathrm{~m}$; temperature, $353 \mathrm{~K}$; linear velocity, $20 \mathrm{~cm} / \mathrm{s}$.

systems into which gases are introduced simultaneously by the automatic sampling system. It takes only $3 \mathrm{~min}$ to analyze all compounds and the results are automatically displayed. The features of the analyzer are shown in Table 5.

The authors are grateful to Dr. Kanohta and the staff of
Table 5 Specifications of portable gas analyzer

\begin{tabular}{ll}
\hline \multicolumn{1}{c}{ Item } & \multicolumn{1}{c}{ Specifications } \\
\hline Analytical time & $3 \mathrm{~min}$ \\
Measurable component & $\mathrm{CH}_{4}, \mathrm{C}_{2} \mathrm{H}_{6}, \mathrm{C}_{3} \mathrm{H}_{8}, i-\mathrm{C}_{4} \mathrm{H}_{10}$, \\
& $n-\mathrm{C}_{4} \mathrm{H}_{10}, \mathrm{CO}_{2}$ \\
Measurable range & $5 \mathrm{ppm}-100 \%$ \\
& $\left(\mathrm{CH}_{4} 20 \mathrm{ppm}-100 \%\right)$ \\
Output form of & compositional values \\
analytical result & $75 \mathrm{ml}\left(100 \mathrm{~kg} / \mathrm{cm}^{2}\right)$ \\
Carrier gas cylinder & $\mathrm{DC} 12 \mathrm{~V} \mathrm{battery}$ \\
Power source & $9 \mathrm{~kg}, 430 \mathrm{~mm} \times 390 \mathrm{~mm} \times 120 \mathrm{~mm}$ \\
Weight and size &
\end{tabular}

Nippon Tylan Co., Ltd. for their contributions to this study.

\section{References}

1. K. Kasahara, D. Terasaki, T. Satomi, T. Hayashiyama and K. Odashima, Proceedings of the Congress of Gas Quality-Specification and Measurement of Physical and Chemical Properties of Natural Gas, Netherlands, 1986, p. 529.

2. S. Saadat and S. Terry, American Laboratory, 5, 90 (1984).

3. G. Lee, C. Ray, R. Siemers and R. Moore, American Laboratory, 10, 111 (1989).

4. H. Itoh, Instrumentation and Automation, 17, 105 (1989).

5. A. van Es, J. Janssen, R. Bally, C. Cramers and J. Rijks, J. High Resolut. Chromatogr., Chromatogr. Commun., 10, 273 (1987).

6. J. de Zeeuw, R. C. M. de Nijs and L. Henrich, $J$. Chromatogr. Sci., 25, 71 (1987).

7. W. K. Al-Thamir, J. High Resolut. Chromatogr., Chromatogr. Commun., 8, 143 (1985).

8. J. de Zeeuw, R. C. M. de Nijs, J. C. Buijten, J. A. Peene and M. Mohnke, Int. Lab., 1988, (December), p. 52.

9. J. de Zeeuw, R. C. M. de Nijs, J. C. Buijten, J. A. Peene and M. Mohnke, J. High Resolut. Chromatogr., Chromatogr. Commun., 11, 162 (1988).

(Received July 19, 1991)

(Accepted September 19, 1991) 